\title{
Inflating the endotracheal tube cuff with saline to confirm correct depth using bedside ultrasonography
}

\author{
Mark O. Tessaro, MDCM; Alexander C. Arroyo, MD; Lawrence E. Haines, MD, MPH; \\ Eitan Dickman, MD
}

\begin{abstract}
Although bedside ultrasonography can accurately distinguish esophageal from tracheal intubation, it is not used to establish the correct depth of endotracheal tube insertion. As indirect sonographic markers of endotracheal tube insertion depth have proven unreliable, a method for visual verification of correct tube depth would be ideal. We describe the use of saline to inflate the endotracheal cuff to confirm correct endotracheal tube depth (at the level of the suprasternal notch) by bedside ultrasonography during resuscitation. This rapid technique holds promise during emergency intubation.
\end{abstract}

\section{RÉSUMÉ}

Bien que l'échographie au chevet des patients permette de distinguer nettement l'intubation œsophagienne de l'intubation endotrachéale, elle n'est toutefois pas utilisée pour déterminer si la sonde a été posée à la bonne profondeur dans la trachée. Comme on ne peut se fier aux marqueurs échographiques indirects de vérification de la profondeur de pénétration de la sonde endotrachéale, l'idéal serait de procéder par vérification visuelle. II sera question ici du gonflement du ballonnet endotrachéal avec une solution saline pour confirmer l'introduction de la sonde à la bonne profondeur (à la hauteur de la fourchette sternale) par échographie au chevet des patients durant les manœuvres de réanimation. Cette technique rapide se révèle prometteuse dans le contexte des intubations d'urgence.

Keywords: bedside ultrasonography, endotracheal tube, intubation

Bedside ultrasonography has proven useful in distinguishing between tracheal or esophageal location of an endotracheal tube (ETT). ${ }^{1-8}$ Air transmits the ultrasound beam poorly, leading to an artifact called "dirty shadowing." With or without an ETT in place, the trachea appears as an area of dirty shadowing on a sonogram because it is filled with air. An ETT incorrectly placed into the esophagus can be detected on a sonogram because two areas of dirty shadowing will then be seen: air within the trachea and within the ETT in the esophagus, which normally contains no air.

Bedside ultrasonography is not used to detect the depth of endotracheal intubation (with the exception of newborns, who possess relatively uncalcified sternal bones, allowing for high-resolution imaging of the distal trachea $\left.{ }^{9-11}\right)$ as the dirty shadowing of air within the ETT cannot be distinguished from the dirty shadowing of air in the trachea beyond the ETT tip. Indirect ultrasound surrogates of correct ETT insertion depth (e.g., bilateral lung sliding and diaphragm movement) are less reliable than chest radiography ${ }^{12-14}$ and are not useful in cases of pneumothorax, subcutaneous emphysema, pleural scarring, pleural effusion, pulmonary malignancies, or ETT obstruction. ${ }^{12}$

Previous reports suggest that inflating the ETT cuff with liquid rather than air (an established and safe practice with applications in many areas of medicine ${ }^{15-26}$ ) allows the cuff to be visualized on a sonogram. ${ }^{27,28}$ An ETT cuff at the level of the suprasternal notch correlates with correct depth of the tip (i.e., just deep to the clavicles. ${ }^{29-32}$ Therefore, sonographic identification of a liquid-filled cuff at the suprasternal notch should confirm the correct depth of intubation. Previous reports of this technique have been limited to cadaver studies $^{28}$ or the operating room and a single radiologist. ${ }^{27} \mathrm{We}$ describe filling the ETT cuff with saline to verify both endotracheal position and correct endotracheal depth during emergency resuscitation.

From the Division of Emergency Ultrasound, Department of Emergency Medicine, Maimonides Medical Center, Brooklyn, NY.

Correspondence to: Dr. Mark Tessaro, Department of Emergency Medicine, Maimonides Medical Center, 4802 10th Avenue, Brooklyn, NY 11219; MTessaro@maimonidesmed.org.

This article has been peer reviewed. 


\section{CASE REPORT}

A 50-year-old man in status epilepticus underwent rapid sequence intubation for airway protection in our emergency department. Bedside ultrasonography in the transverse plane at the suprasternal notch revealed a single area of dirty shadowing, confirming tracheal rather than esophageal intubation. Bilateral breath sounds were noted, and capnography revealed the presence of exhaled carbon dioxide. The cuff of the ETT was inflated with $10 \mathrm{~mL}$ of air, and a portable chest radiograph was ordered.

As the effect of the paralytic agent subsided, the tonic-clonic activity resumed, followed by brief oxygen desaturation. Concerned that the convulsions may have dislodged the ETT, bedside ultrasonography was attempted to confirm the position of the ETT.

A sonogram of the anterior neck was performed at the level of the suprasternal notch (Figure 1). With the probe in a longitudinal orientation, the characteristic appearance of the thyroid cartilage and tracheal rings was observed, with an underlying column of air that, as expected, obscured any evidence of the ETT or cuff (Figure 2). The cuff was deflated, with no significant change noted in the appearance of the ultrasound image (Figure 3).

The cuff was then inflated with $7 \mathrm{~mL}$ of saline while the probe was held in a transverse orientation at the suprasternal notch. The cuff was readily visualized as an expanding anechoic sphere transiently containing hyperechoic bubbles (Appendix, online version only), in the single area of dirty shadowing corresponding to the trachea. The probe was returned to the longitudinal orientation, revealing the presence of two hyperechoic parallel lines within the trachea (Figure 4). These lines represent the outer and inner surfaces of the anterior aspect of the ETT. ${ }^{6}$ The saline within the cuff acted as an acoustic window allowing visualization of the tube, which had not been possible when the cuff was filled with air. When the saline was evacuated, these parallel lines disappeared. Finally, the cuff was reinflated with air, which was left in place for the duration of the patient's intubation. The sonographic examination was completed in less than 2 minutes.

The subsequent chest radiograph confirmed that the tip of the ETT was correctly positioned just deep to the inferior border of the clavicles, at the level of the T3 vertebra.

\section{DISCUSSION}

ETT malposition remains a significant issue in emergency intubation, occurring in $20 \%$ of cases. . $^{33,34}$ Inadvertent endobronchial intubation is associated with serious complications, such as hypoxemia and
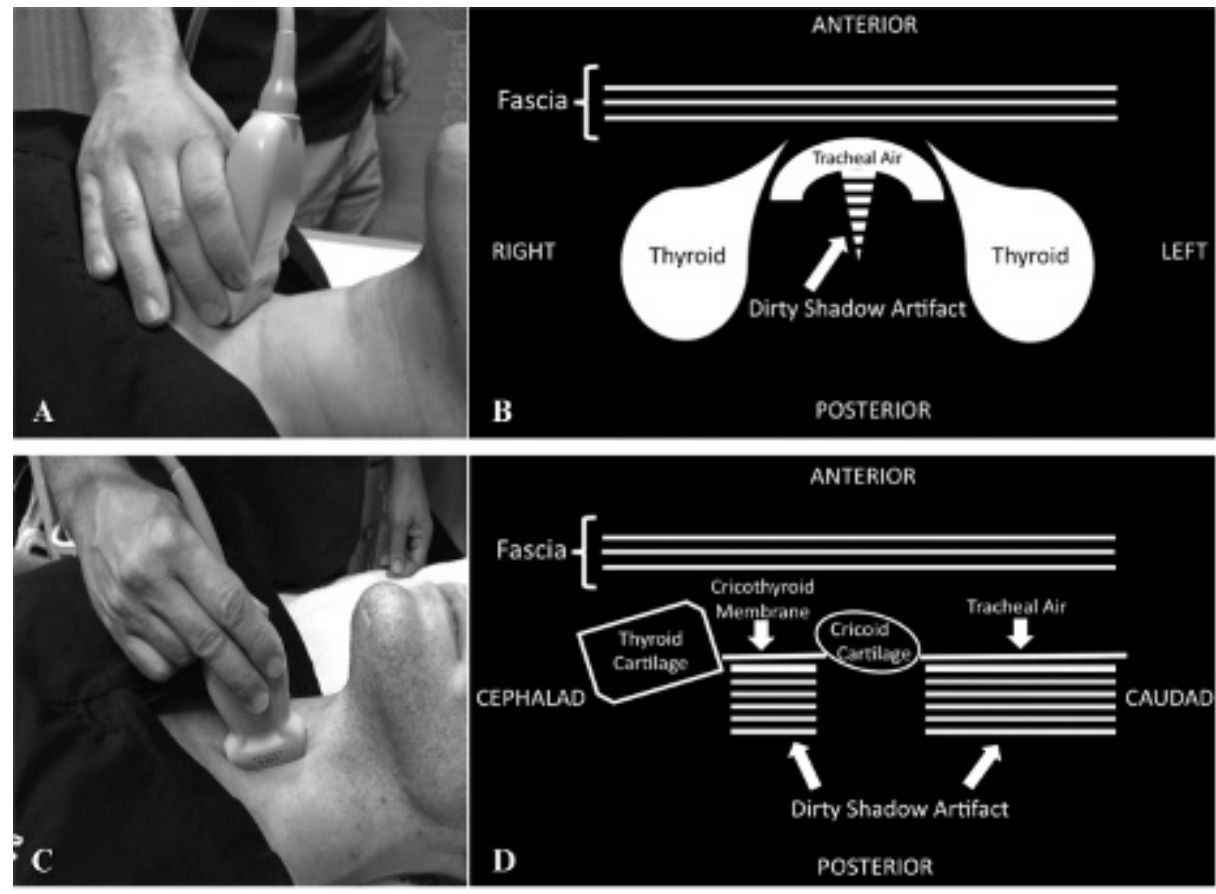

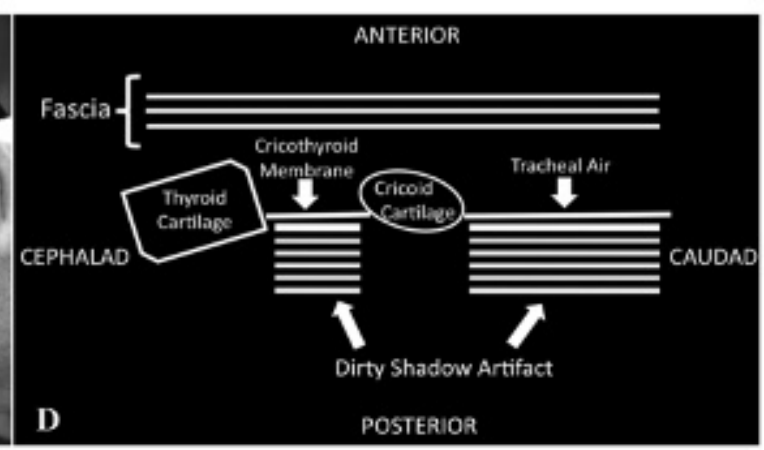

Figure 1. Technique for ultrasound confirmation of endotracheal tube placement. $A$, Transverse transducer position. The probe is held perpendicular to the anterior neck at the level of the suprasternal notch. The probe marker is toward the patient's right. $B$, Diagram of airway structures as they appear on ultrasound imaging in the transverse plane. $C$, Longitudinal transducer position. The probe is held perpendicular to the anterior neck, over the trachea. The probe marker is toward the patient's head, whereas the unmarked side of the probe rests in the suprasternal notch. $D$, Diagram of airway structures as they appear on ultrasound imaging in the longitudinal plane. 


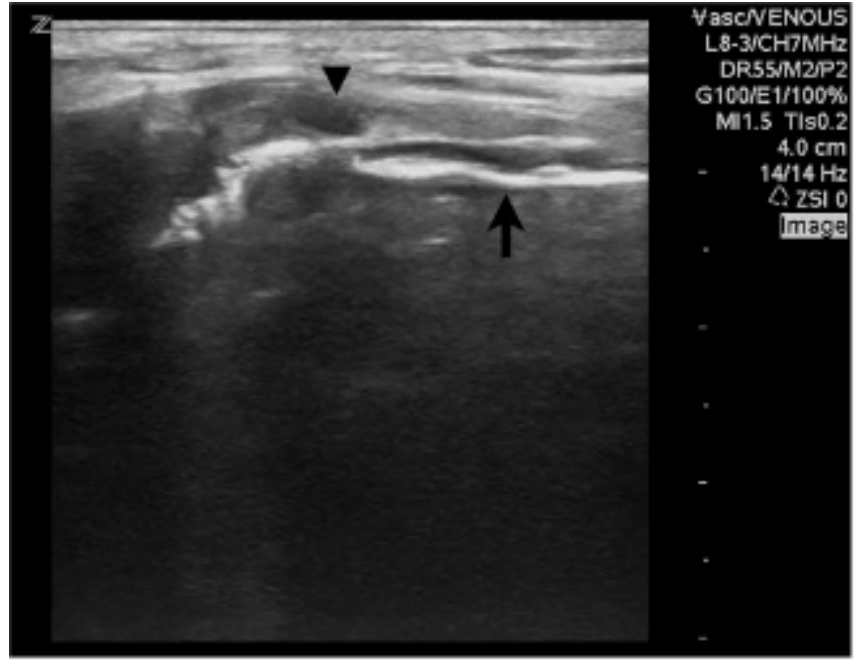

Figure 2. Longitudinal view of the intubated trachea, with the cuff of the endotracheal tube inflated with air. The ultrasound probe marker is toward the patient's head. The hypoechoic ovoid structure indicated by the arrowhead corresponds to the anterior cricoid cartilage in cross-section. The hyperechoic horizontal line indicated by the arrow represents the air-mucosa interface of the anterior trachea. Neither the endotracheal tube nor its cuff is visible on the sonogram.

barotrauma. On the other hand, an ETT placed too high in the trachea carries risks of accidental extubation and cuff-induced vocal cord injury. Confirmation of correct position can be difficult in the emergency department: background noise interferes with auscultation, ${ }^{35-37}$ capnography does not distinguish between endobronchial and endotracheal intubation, ${ }^{38,39}$ and radiographic studies entail some finite delays. ${ }^{12}$ Direct or fibre-optic visualization is also imperfect. ${ }^{40}$

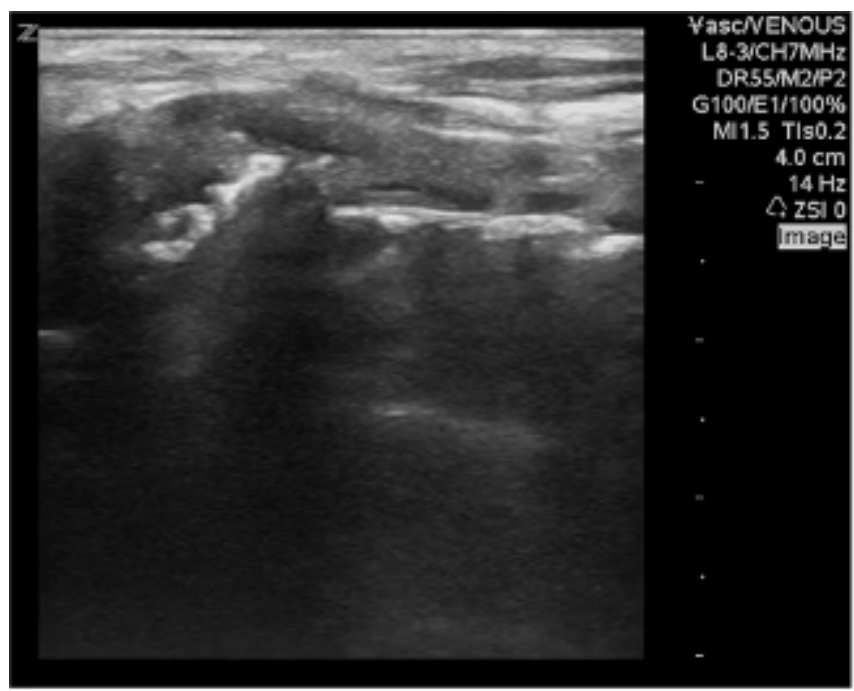

Figure 3. Longitudinal view of the intubated trachea, with the endotracheal tube cuff deflated. There is no notable difference compared to Figure 2.

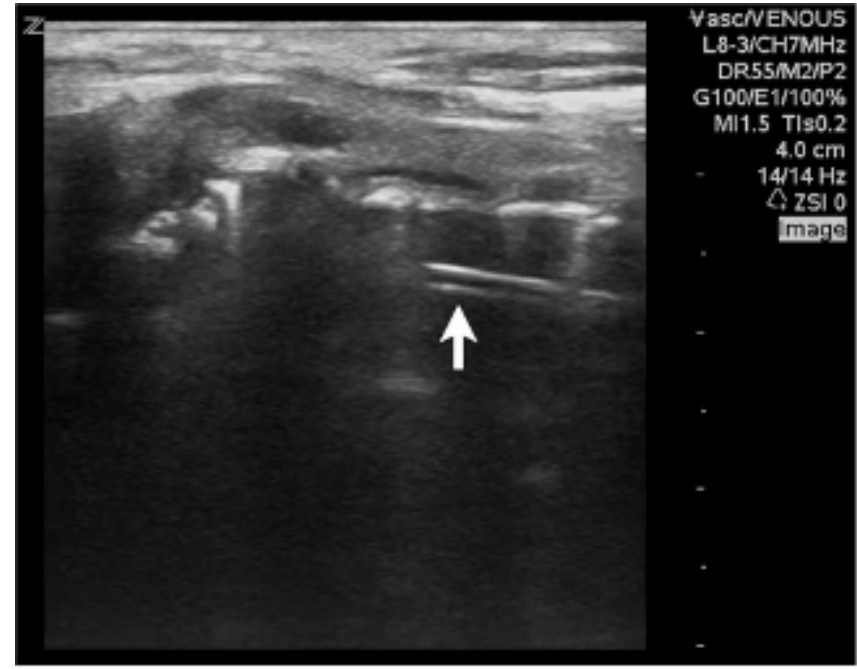

Figure 4. Longitudinal view of the intubated trachea, with the cuff of the endotracheal tube inflated with saline. The saline in the anterior portion of the cuff provides an acoustic window through which the anterior wall of the endotracheal tube can be seen (the two hyperechoic parallel lines indicated by the arrow).

The bedside ultrasound technique described here allowed rapid confirmation of correct ETT insertion depth during resuscitation.

The optimal depth for the tip of the ETT is at the midpoint of the trachea, halfway between the vocal cords and the carina. ${ }^{41}$ In practice, $5 \pm 2 \mathrm{~cm}$ from the carina is commonly used as a range for acceptable depth of the ETT tip. ${ }^{42}$ An ETT tip at the level of the inferior border of the clavicles will fall within this acceptable range.

Chest radiography is the most commonly used test to confirm ETT depth but has a number of drawbacks besides delay. It requires lifting of the patient to place the $\mathrm{x}$-ray film under them, a procedure well known for causing dislodgment of the ETT. ${ }^{9,27}$ It requires interruption of chest compressions during resuscitation and involves ionizing radiation. The chest $\mathrm{x}$-ray result also only reflects the position of the ETT at the time of the radiograph, and the tip is known to move $1 \pm 4 \mathrm{~cm}$ during flexion and extension of the neck..$^{43}$

Bedside ultrasonography involves no radiation, requires no patient repositioning, gives an instantaneous result, and can be repeated as needed. It is already established as an accurate test to differentiate tracheal from esophageal intubation. ${ }^{1-8}$

An ETT cuff that is located at the level of the suprasternal notch correlates to correct depth of ETT insertion..$^{29-32} \mathrm{~A}$ cuff filled with air, however, cannot be reliably distinguished from the surrounding air-filled 
trachea. A pioneering anesthesiology study in 1987 reported the use of saline rather than air to allow cuff visualization by ultrasonography. ${ }^{27}$ This technique was not adopted into clinical practice, however, perhaps due to the limited availability of bedside ultrasonography at the time. A more recent report in a cadaver study showed that novice sonographers could accurately identify a saline-inflated ETT cuff at the level of the suprasternal notch. ${ }^{28}$ We report temporarily inflating an ETT cuff with saline to directly confirm correct ETT depth during resuscitation.

The bedside ultrasound examination described above is easy to learn, provides an immediate result, and has the potential to replace many of the chest radiographs that are performed solely for ETT placement confirmation. This technique does require temporary deflation of an ETT cuff. We recommend suctioning the oropharynx prior to performing this technique to limit the risk of secretion aspiration.

\section{CONCLUSION}

This case report describes the temporary inflation of an ETT cuff with saline to allow sonographic confirmation of correct depth of ETT insertion during resuscitation. This technique holds promise as a primary confirmation method for ETT placement.

Competing interests: None declared.

\section{REFERENCES}

1. Milling TJ, Jones $M$, Khan T, et al. Transtracheal 2-D ultrasound for identification of esophageal intubation. 7 Emerg Med 2007;32:409-14, doi:10.1016/j.jemermed.2006.08.022.

2. Werner SL, Smith CE, Goldstein JR, et al. Pilot study to evaluate the accuracy of ultrasonography in confirming endotracheal tube placement. Ann Emerg Med 2007;49:7580, doi:10.1016/j.annemergmed.2006.07.004.

3. Muslu B, Sert H, Kaya A, et al. Use of sonography for rapid identification of esophageal and tracheal intubations in adult patients. 7 Ultrasound Med 2011;30:671-6.

4. Chou HC, Tseng WP, Wang CH, et al. Tracheal rapid ultrasound exam (T.R.U.E.) for confirming endotracheal tube placement during emergency intubation. Resuscitation 2011;82:1279-84, doi:10.1016/j.resuscitation.2011.05.016.

5. Sağlam C, Ünlüer EE, Karagöz A. Confirmation of endotracheal tube position during resuscitation by bedside ultrasonography. Am 7 Emerg Med 2013;31:248-50, doi:10. 1016/j.ajem.2012.08.002.

6. Galicinao J, Bush AJ, Godambe SA. Use of bedside ultrasonography for endotracheal tube placement in pediatric patients: a feasibility study. Pediatrics 2007;120:1297-303, doi:10.1542/peds.2006-2959.
7. Marciniak B, Fayoux P, Hebrard A, et al. Airway management in children: ultrasonography assessment of tracheal intubation in real time? Anesth Analg 2009;108:461-5, doi:10.1213/ane.0b013e31819240f5.

8. Mora-Matilla M, Alonso-Quintela P, Oulego-Erroz I, et al. Is ultrasound a feasible tool to verify endotracheal tube position in neonates? Resuscitation 2013;84:e19-20, doi:10. 1016/j.resuscitation.2012.09.026.

9. Dennington D, Vali P, Finer $\mathrm{NN}$, et al. Ultrasound confirmation of endotracheal tube position in neonates. Neonatology 2012;102:185-9, doi:10.1159/000338585.

10. Slovis TL, Poland RL. Endotracheal tubes in neonates: sonographic positioning. Radiology 1986;160:262-3.

11. Lingle PA. Sonographic verification of endotracheal tube position in neonates: a modified technique. 7 Clin Ultrasound 1988;16:605-9, doi:10.1002/jcu.1870160816.

12. Sim SS, Lien WC, Chou HC, et al. Ultrasonographic lung sliding sign in confirming proper endotracheal intubation during emergency intubation. Resuscitation 2012;83:307-12, doi:10.1016/j.resuscitation.2011.11.010.

13. Kerrey BT, Geis GL, Quinn AM, et al. A prospective comparison of diaphragmatic ultrasound and chest radiography to determine endotracheal tube position in a pediatric emergency department. Pediatrics 2009;123:e103944, doi:10.1542/peds.2008-2828.

14. Youssefian A, Turner E, Breazeale S, et al. Three-window bedside ultrasound versus chest radiography for confirmation of endotracheal tube placement. Poster session presented at American Institute of Ultrasound in Medicine Annual Conference; 2013 Apr 6-10; New York, NY.

15. Navarro RM, Baughman VL. Lidocaine in the endotracheal tube cuff reduces postoperative sore throat. 7 Clin Anesth 1997;9:394-7, doi:10.1016/S0952-8180(97)00068-8.

16. Mitchell V, Adams T, Calder I. Choice of cuff inflation medium during nitrous oxide anaesthesia. Anaesthesia 1999; 54:32-6, doi:10.1046/j.1365-2044.1999.00646.x.

17. Porter NE, Sidou V, Husson J. Postoperative sore throat: incidence and severity after the use of lidocaine, saline, or air to inflate the endotracheal tube cuff. AANA 7 1999;67:49-52.

18. Bennett MH, Isert PR, Cumming RG. Postoperative sore throat and hoarseness following tracheal intubation using air or saline to inflate the cuff-a randomized controlled trial. Anaesth Intensive Care 2000;28:408-13.

19. Ahmad NL, Norsidah AM. Change in endotracheal tube cuff pressure during nitrous oxide anaesthesia: a comparison between air and distilled water cuff inflation. Anaesth Intensive Care 2001;29:510-4.

20. Combes X, Schauvliege F, Peyrouset O, et al. Intracuff pressure and tracheal morbidity: influence of filling with saline during nitrous oxide anesthesia. Anesthesiology 2001;95: 1120-4, doi:10.1097/00000542-200111000-00015.

21. Malhotra S, Singh M, Malhotra N. Tracheal morbidity following tracheal intubation: comparison of air, saline and lignocaine used for inflating cuff. 7 Anaesthesiol Clin Pharmacol 2007;23:163-7.

22. Shroff PP, Patil V. Efficacy of cuff inflation media to prevent postintubation-related emergence phenomenon: air, saline and alkalinized lignocaine. Eur 7 Anaesthesiol 2009;26:45862, doi:10.1097/EJA.0b013e32832403fa. 
23. Behzadi M, Hajimohamadi F, Alagha AE, et al. Endotracheal tube cuff lidocaine is not superior to intravenous lidocaine in short pediatric surgeries. Int 7 Pediatr Otorbinolaryngol 2010;74:486-8, doi:10.1016/j.ijporl. 2010.01.025.

24. Dadure C, Granier M, Bringuier S, et al. [Comparison of saline, air, and a mixture oxygen-nitrous oxide for endotracheal cuff tracheal tube inflation in children? A prospective randomized trial]. Ann Fr Anesth 2010;29:687-92, doi:10.1016/j.annfar.2010.06.022.

25. Matsuo K, Akata T, Yamaura K, et al. [Intraoperative monitoring of pressure within saline-filled, endotracheal tube cuff in adult patients undergoing $\mathrm{CO} 2$ laser laryngomicrosurgery]. Masui 2002;51:482-8.

26. Agrawal G, Agrawal M, Dali JS. Endotracheal tube cuff pressure with different media for cuff inflation and laryngotracheal morbidity. 7 Anaesthesiol Clin Pharmacol 2008;24:165.

27. Raphael DT, Conard FU. Ultrasound confirmation of endotracheal tube placement. I Clin Ultrasound 1987;15: 459-62, doi:10.1002/jcu.1870150706.

28. Uya A, Spear D, Patel K, et al. Can novice sonographers accurately locate an endotracheal tube with a saline-filled cuff in a cadaver model? A pilot study. Acad Emerg Med 2013; 19:361-4, doi:10.1111/j.1553-2712.2012.01306.x.

29. Pattnaik SK, Bodra R. Ballotability of cuff to confirm the correct intratracheal position of the endotracheal tube in the intensive care unit. Eur 7 Anaesthesiol 2000;17:587-90, doi:10.1097/00003643-200009000-00008.

30. Pollard RJ, Lobato EB. Endotracheal tube location verified reliably by cuff palpation. Anesth Analg 1995;81:135-8.

31. Okuyama M, Imai $M$, Sugawara $K$, et al. [Finding appropriate tube position by the cuff palpation method in children]. Masui 1995;44:845-8.

32. Goldman JM, Armstrong JP, Vaught LE, et al. A new method for identifying the depth of insertion of tracheal tubes. Biomed Sci Instrum 1995;31:225-8.

33. Bissinger $U$, Lenz G, Kuhn W. Unrecognized endobronchial intubation of emergency patients. Ann Emerg Med 1989;18:853-5, doi:10.1016/S0196-0644(89)80211-2.

34. Geisser W, Maybauer DM, Wolff H, et al. Radiological validation of tracheal tube insertion depth in out-of-hospital and in-hospital emergency patients. Anaesthesia 2009;64:9737, doi:10.1111/j.1365-2044.2009.06007.x.

35. Sitzwohl C, Langheinrich A, Schober A, et al. Endobronchial intubation detected by insertion depth of endotracheal tube, bilateral auscultation, or observation of chest movements: randomised trial. BM7 2010;341:c5943, doi:10.1136/bmj.c5943.

36. Harris EA, Arheart KL, Penning DH. Endotracheal tube malposition within the pediatric population: a common event despite clinical evidence of correct placement. Can 7 Anaesth 2008;55:685-90, doi:10.1007/BF03017744.

37. Klepper ID, Webb RK, Van der Walt JH, et al. The Australian Incident Monitoring Study. The stethoscope: applications and limitations-an analysis of 2000 incident reports. Anaesth Intensive Care 1993;21:575-8.

38. Li J. Capnography alone is imperfect for endotracheal tube placement confirmation during emergency intubation. 7 Emerg Med 2001;20:223-9, doi:10.1016/S0736-4679(00)00 318-8.

39. Leong MT, Ghebrial J, Sturmann K. The effect of vinegar on colorimetric end-tidal carbon dioxide determination after esophageal intubation. 7 Emerg Med 2005;28:5-11, doi:10. 1016/j.jemermed.2004.06.012.

40. Rudraraju P, Eisen LA. Analytic review: confirmation of endotracheal tube position: a narrative review. 7 Intensive Care Med 2009;24:283-92, doi:10.1177/0885066609340501.

41. Conrardy PA, Goodman LR, Lainge F, et al. Alteration of endotracheal tube position. Flexion and extension of the neck. Crit Care Med 1976;4:7-12, doi:10.1097/00003246197601000-00002.

42. Goodman LR, Conrardy PA, Laing F, et al. Radiographic evaluation of endotracheal tube position. $A 7 R \quad A m \mathcal{F}$ Roentgenol 1976;127:433-4, doi:10.2214/ajr.127.3.433.

43. Yap SJ, Morris RW, Pybus DA. Alterations in endotracheal tube position during general anaesthesia. Anaesth Intensive Care 1994;22:586-8.

APPENDIX: Video of the Endotracheal Tube Cuff during Inflation with Saline. Transverse View of the Intubated Trachea at the Level of the Suprasternal Notch. 